\title{
Optimization of Highly Efficient and Eco-Friendly EA- Substituted Tin Based Perovskite Solar Cell with Different Hole Transport Material
}

\section{Rashi Chandel}

Punjab Engineering College: PEC University of Technology

deepak Punetha ( $\sim$ punetha@iitb.ac.in )

Indian Institute of Technology Bombay https://orcid.org/0000-0002-5737-2900

Divya Dhawan

Punjab Engineering College: PEC University of Technology

Neena Gupta

Punjab Engineering College: PEC University of Technology

\section{Research Article}

Keywords: lead-free perovskite solar cell, absorber layer, hole transport layer, recombination, defect density, simulation.

Posted Date: January 5th, 2022

DOl: https://doi.org/10.21203/rs.3.rs-995774/v1

License: (9) This work is licensed under a Creative Commons Attribution 4.0 International License. Read Full License 


\title{
Optimization of highly efficient and Eco-friendly EA-substituted tin based perovskite solar cell with different hole transport material
}

\author{
Rashi Chandel ${ }^{1}$, Deepak Punetha ${ }^{1,2}$, Divya Dhawan $^{1}$, Neena Gupta ${ }^{1}$ \\ ${ }^{1}$ Department of Electronics and Communication Engineering, Punjab Engineering College (Deemed to be University), Chandigarh, 160012, \\ India \\ ${ }^{2}$ Department of Electrical Engineering, Indian Institute of Technology Bombay, Powai, Mumbai, Maharashtra, 400076, India
}

\begin{abstract}
The perovskite absorber layer are considered highly efficient solar cell for low-cost electricity production. In this research work, an EA-substituted tin based perovskite solar cell with different hole transport material (PEDOT: PSS, $\mathrm{Cu}_{2} \mathrm{O}, \mathrm{CuI}, \mathrm{CZTSe}$ ) have been investigated using device simulation software. The effects of absorber thickness, defect density, operating temperature, J-V characteristics, and Quantum efficiency have been considered to enhance the performance of solar cell. To confirm the feasibility and validate the study, all the simulation results were compared with reported experiment data. According to the experimental work based on $\left(\mathrm{FA}_{0.9} \mathrm{EA}_{0.1}\right)_{0.98} \mathrm{EDA}_{0.01} \mathrm{SnI}_{3}$ absorber layer, maximum of $13 \%$ efficiency is achieved with PEDOT: PSS as the HTM. Whereas we have further optimized performance parameters and found the superior response $\left(\mathrm{Voc}=0.8851 \mathrm{~V}, \mathrm{Jsc}=27.24 \mathrm{~mA} / \mathrm{cm}^{2}, \mathrm{FF}=77.91 \%\right.$, and $\mathrm{PCE}=18.78 \%$ ) while opted $\mathrm{Cu}_{2} \mathrm{O}$ as the hole transport material. This device structure $\mathrm{FTO} / \mathrm{Cu}_{2} \mathrm{O} /\left(\mathrm{FA}_{0.9} \mathrm{EA}_{0.1}\right)_{0.98} \mathrm{EDA}_{0.01} \mathrm{SnI}_{3} / \mathrm{IDL} / \mathrm{PCBM} / \mathrm{C} 60 / \mathrm{Au}$ provides the more efficient, reliable solution for replacing the lead-based perovskite solar cell. This study will aid researcher in a reasonable choice of materials and to predict the behavior of high performance solar cell before undergoing the fabrication process.
\end{abstract}

Keywords-lead-free perovskite solar cell, absorber layer, hole transport layer, recombination, defect density, simulation.

\section{INTRODUCTION}

The demand for clean and renewable energy is increasing each day. With the increasing demand for energy consumption, solar power is considered one of the promising technologies. Solar cell is a device that is used to convert solar energy into electricity. The monocrystalline and polycrystalline are the first-generation solar cells that are currently engaged in industrial applications due to its high efficiency. But due to its high cost, large operation voltage, and environmental pollution leads to second generation solar cells [1-2]. Cadmium telluride and copper indium gallium selenium thin-fil solar cells achieved good efficiency but again the production cost is high. Perovskite Solar cells (PSCs) have shown excellent performance nowadays. It has been grabbing the attention of researchers worldwide due to its high-power conversion efficiency. As of now, lead-based PSCs have achieved power conversion efficiency of $26.1 \%$ [1-4]. Perovskite solar cells after attaining high conversion efficiency come up as a strong competitor of silicon-based solar cells in the photovoltaic industry [5]. Therefore, several considerable efforts have been done to replace toxic elements with non-toxic elements like Bi, Ge, Ag, and Sn. Among all these alternatives, $\mathrm{Sn}$ is considered the best substitute of lead in perovskite solar cells due to its excellent optoelectronic properties and low band gap [6]. Sn overcomes the toxicity problem, is considered an eco-friendly solar cell, and provides good efficiency. Research is still going on to overcome the instability issues of tin-based solar cells. Researchers are adding various components in the absorber layer to overcome the instability issues (self-doping) of tin-based perovskite solar cells. EA-substituted tin-based solar cell is one of the most stable and environment-friendly devices.

Implementation of various tin-based absorber layers like $\mathrm{CsSnI}_{3}, \mathrm{FASnI}_{3}$, and $\mathrm{MASnI}_{3}$ has come up with a solution of replacing toxic element lead $(\mathrm{Pb})$. These layers provide an optimized power conversion efficiency of $9.10 \%$, 9.99\%, and $12.90 \%$ respectively [7]. Manish Kumar et al. have reported the study of $\mathrm{FASnI}_{3}$ based solar cell and they have achieved PCE of around $19.08 \%$, short circuit current density of $31.20 \mathrm{~mA} / \mathrm{cm}^{2}$, fill factor of $33.72 \%$ after optimizing various parameters of ETL $\left(\mathrm{TiO}_{2}\right)$, HTL (Spiro-OMeTAD) and absorber layer [8]. Sn (tin) based perovskite solar cells (PSCs) have certain limitations. Tin is easily get oxidized from $\mathrm{Sn} 2+$ to $\mathrm{Sn} 4+$, leading to self-doping. It has a detrimental effect on its performance. It leads to low PCE and poor performance, so necessary steps are taken to reduce or eliminate this unwanted process called self-doping arises due to oxidation of tin [9]. Tin-based perovskite solar cells (PSCs) have a proper optical bandgap $(1.2-1.4 \mathrm{eV})$ which is in the close proximation of Shockley Queisser Limit $(\approx 1.3 \mathrm{eV})$. This ideal bandgap can be considered as the biggest motive toward the development of Sn-based or Pb-free perovskite solar cells. Tin-based PSCs provide fast crystallization and low defect tolerance. The self-doping process arising due to unwanted oxidation of tin material causes recombination of excitons (electronhole) in perovskites [10-13].

In the present simulation work, we have used $\left(\mathrm{FA}_{0.9} \mathrm{EA}_{0.1}\right)_{0.98} \mathrm{EDA}_{0.01} \mathrm{SnI}_{3}$ absorber layer, where EAI (ethyl ammonium iodide) helps to match the energy level which improves crystallinity. Ethylammonium (EA) is used to enhance the extraction process of the electron transport layer and hole transport layer [14]. Hence, it will reduce the charge carrier recombination. Thereby, increasing the lifetime of charge carriers (electrons and hole) and conclusively will lead to increase in the lifetime of perovskite solar cells (PSCs). $\left(\mathrm{FA}_{0.9} \mathrm{EA}_{0.1}\right)_{0.98} \mathrm{EDA}_{0.01} \mathrm{SnI}_{3}$ based PSCs have been examined and analyzed the impact of thickness, defect density of absorber layer with different hole transport materials. Various hole transport materials such as Poly $(3,4-$ ethylenedioxythiophene)-poly(styrene sulfonate) (PEDOT: PSS), cuprous oxide $\left(\mathrm{Cu}_{2} \mathrm{O}\right)$, Copper(I) iodide (CuI), and copper 
zinc tin selenide (CZTSe) are investigated using simulation software. Poly(3-hexylthiophene) (PCBM) and C60 are used as an ETL (Electron transport layer) in the device structure. Device simulation is done for $\mathrm{FTO} / \mathrm{HTM} /\left(\mathrm{FA}_{0.9} \mathrm{EA}_{0.1}\right)_{0.98} \mathrm{EDA}_{0.01} \mathrm{SnI}_{3} / \mathrm{IDL} / \mathrm{PCBM} / \mathrm{C} 60 / \mathrm{Au}$ inverted structure with parameters of each layer using SCAPS- 1D and results of four different structures are analyzed under AM1.5G solar spectrum at $1000 \mathrm{~W} / \mathrm{m}^{2}$.

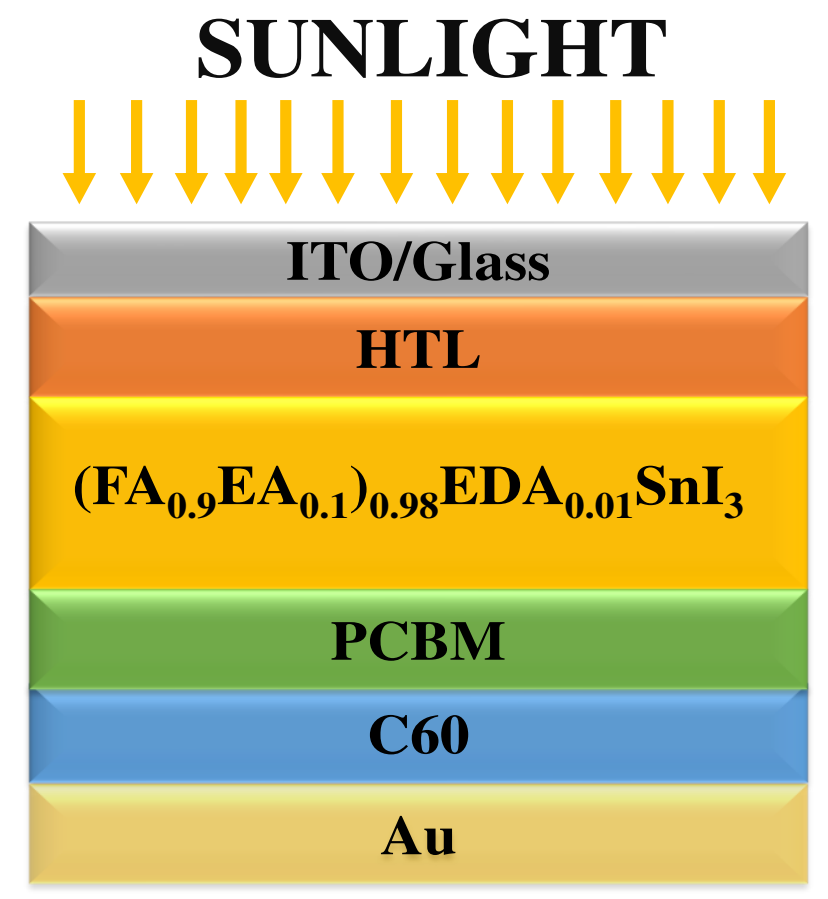

Fig.1. Device configuration of simulated Perovskite Solar Cell

\section{DEVICE STRUCTURE AND SIMULATION METHODOLOGY}

\section{A. Device Structure}

Four structures having different hole transport material (HTM) is simulated using SCAPS 1-D (ver. 3.3.10) under AM1.5G illumination with an incident light power of $1000 \mathrm{~W} / \mathrm{m}^{2}$. This simulation software is developed at the University of Gent, Belgium to scrutinize the performance of the tin-based solar cell. In SCAPS 1-D, all the calculations for simulations are carried out using three fundamental equations: Poisson equation, hole continuity equation, and electron continuity equation. Using SCAPS 1-D, the heterostructure of solar cells can be designed using seven different layers and we can illuminate the device using light and dark environmental conditions [15,16].

This structure is composed of $\quad$ FTO/HTM $\quad(30 \mathrm{~nm}) /\left(\mathrm{FA}_{0.9} \mathrm{EA}_{0.1}\right)_{0.98} \mathrm{EDA}_{0.01} \mathrm{SnI}_{3}(550 \mathrm{~nm}) / \mathrm{IDL}(5 \mathrm{~nm}) / \mathrm{PCBM}$ $(30 \mathrm{~nm}) / \mathrm{C} 60(30 \mathrm{~nm}) / \mathrm{Au}$ is shown in the figure 1. In this device structure, $\left(\mathrm{FA}_{0.9} \mathrm{EA}_{0.1}\right)_{0.98} \mathrm{EDA}_{0.01} \mathrm{SnI}_{3}$ is the perovskite absorber layer (PAL), inserted between the hole transport layer (HTL) and the electron transport layer (ETL). Interface defect layer (IDL) is inserted between perovskite absorber layer (PAL) and PCBM interface to consider interface recombination between holes at the energy of valence band (Ev) of the perovskite absorber layer and electrons at energy of conduction band (Ec) of PCBM layer. FTO is used as a front contact and gold $(\mathrm{Au})$ is used as the back contact. Energy Band diagram of four structures having different hole transport material (HTM) can be seen in fig. 2. Case a), b), c), d) represents the band diagram of ITO/HTM/(FA $\left.{ }_{0.9} \mathrm{EA}_{0.1}\right)_{0.98} \mathrm{EDA}_{0.01} \mathrm{SnI}_{3} / \mathrm{IDL} / \mathrm{PCBM} / \mathrm{C} 60 / \mathrm{Au}$ structure, where PEDOT: PSS, $\mathrm{Cu}_{2} \mathrm{O}$, CuI, and CZTSe act as a hole transport layers (HTLs). ETM and HTM are used to extract the electrons and holes from the absorber layer and they should have high charge carrier mobility.

For proper transport of electrons, the minimum level of the conduction band of the electron transport layer (ETL) must lie below than minimum level of the conduction band of the perovskite layer. Similarly, in the case of hole transport layer, the maximum level of valence band of hole transport layer must lie above that of the perovskite layer [17]. Out of different HTL, $\mathrm{Cu}_{2} \mathrm{O}$ is performing better because it has better band alignment with the perovskite layer and back-contact and high charge carrier mobility. However, it is already shown in the literature that $\mathrm{Cu}_{2} \mathrm{O}$ can be easily fabricated using low-temperature solution method. 


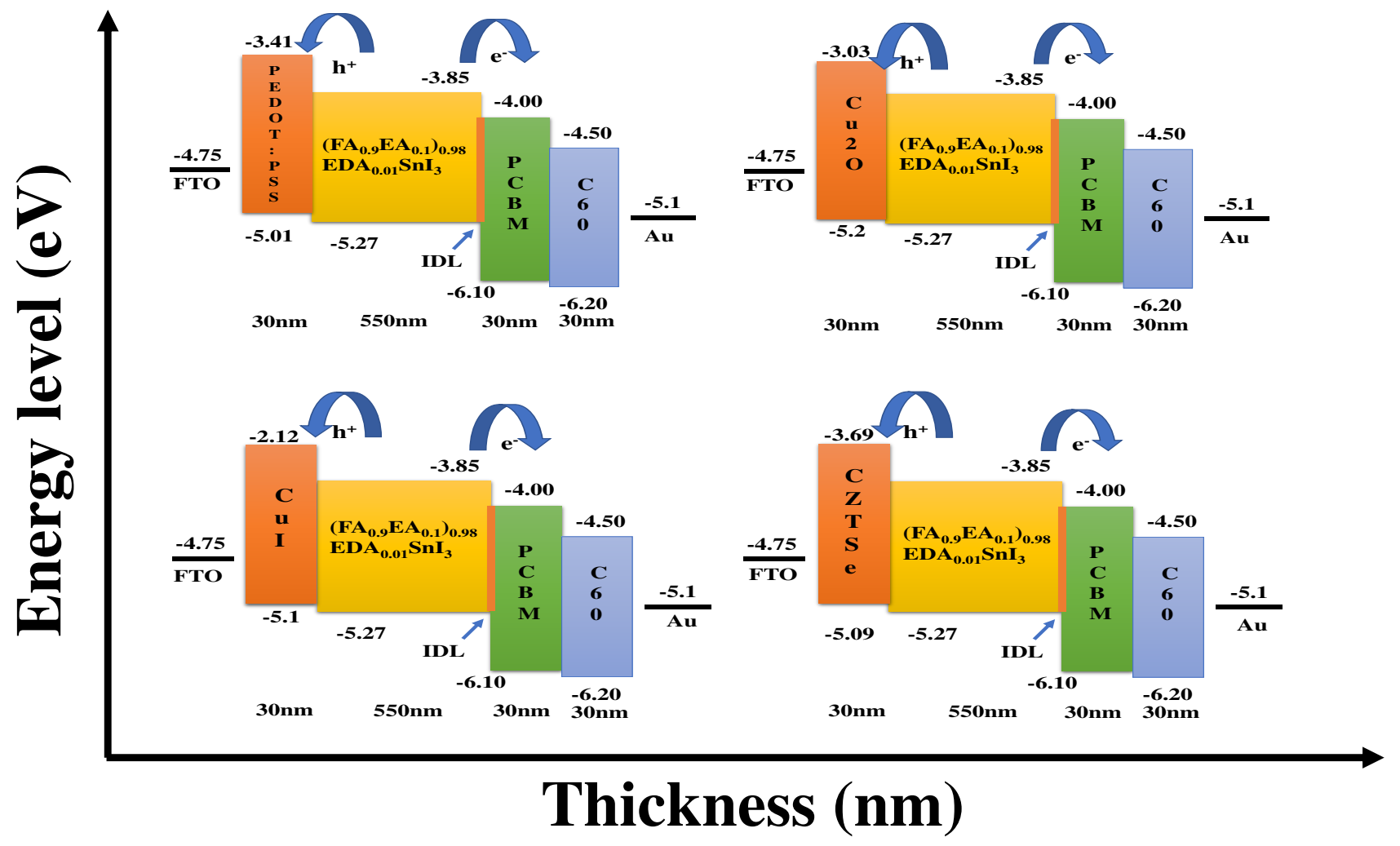

Fig.2. Energy band alignment diagram of different hole transport layer for the simulation of $\left(\mathrm{FA}_{0.9} \mathrm{EA}_{0.1}\right)_{0.98} \mathrm{EDA}_{0.01} \mathrm{SnI}_{3}$ based perovskite solar cell (a) PEDOT:PSS (b) $\mathrm{Cu}_{2} \mathrm{O}$ (c) $\mathrm{CuI}$ (d) CZTSe

\section{B. SCAPS simulation methodology}

Various parameters have been used to perform this research work and they are obtained from various experimental and theoretical research papers. These parameters are summarized in table 1. The thickness of absorber layer is optimized at 550nm whereas the thickness of ETL and HTL is best suited at $30 \mathrm{~nm}$. The bandgap of $\left(\mathrm{FA}_{0.9} \mathrm{EA}_{0.1}\right)_{0.98} \mathrm{EDA}_{0.01} \mathrm{SnI}_{3}$ is $1.42 \mathrm{eV}$. The total defect density is set at $1 \times 10^{14} \mathrm{~cm}^{-3}$. As we increase the defect density, the overall efficiency of the device reduces. All the other parameters of HTL, ETL, and perovskite absorber layer are given in Table 1 and Table 2.

Table 1. Basic parameters of each layer of the perovskite solar cell $[14,16,17,18,19]$

\begin{tabular}{|c|c|c|c|c|c|}
\hline Parameters & $\mathrm{Cu}_{2} \mathrm{O}$ & $\left(\mathrm{FA}_{0.9} \mathrm{EA}_{0.1}\right)_{0.98} \mathrm{EDA}_{0.01} \mathrm{SnI}_{3}$ & IDL & PCBM & C60 \\
\hline Thickness $(\mu \mathrm{m})$ & 0.03 & 0.550 & 0.005 & 0.03 & 0.03 \\
\hline Bandgap (eV) & 2.17 & 1.42 & 1.07 & 2.1 & 1.7 \\
\hline Electron affinity $(\mathrm{eV})$ & 3.2 & 3.67 & 4.0 & 3.9 & 3.9 \\
\hline Dielectric permittivity (relative) & 7.1 & 8.2 & 8.2 & 3.9 & 4.2 \\
\hline $\begin{array}{l}\text { CB effective density of states } \\
\left(1 / \mathrm{cm}^{3}\right)\end{array}$ & $2.5 \times 10^{18}$ & $1 \times 10^{18}$ & $2.2 \times 10^{18}$ & $2.5 \times 10^{21}$ & $8 \times 10^{19}$ \\
\hline $\begin{array}{l}\text { VB effective density of states } \\
\left(1 / \mathrm{cm}^{3}\right)\end{array}$ & $1.8 \times 10^{18}$ & $1 \times 10^{18}$ & $1.8 \times 10^{19}$ & $2.5 \times 10^{21}$ & $8 \times 10^{19}$ \\
\hline Electron thermal velocity $(\mathrm{cm} / \mathrm{s})$ & $1 \times 10^{7}$ & $1 \times 10^{7}$ & $1 \times 10^{7}$ & $1 \times 10^{7}$ & $1 \times 10^{7}$ \\
\hline Hole thermal velocity $(\mathrm{cm} / \mathrm{s})$ & $1 \times 10^{7}$ & $1 \times 10^{7}$ & $1 \times 10^{7}$ & $1 \times 10^{7}$ & $1 \times 10^{7}$ \\
\hline Electron mobility $\left(\mathrm{cm}^{2} / \mathrm{Vs}\right)$ & $2 \times 10^{2}$ & $9.74 \times 10^{2}$ & $9.27 \times 10^{-3}$ & $2 \times 10^{-2}$ & $8 \times 10^{-2}$ \\
\hline Hole mobility $\left(\mathrm{cm}^{2} / \mathrm{Vs}\right)$ & $8 \times 10^{2}$ & $2.13 \times 10^{2}$ & $9.27 \times 10^{-3}$ & $2 \times 10^{-2}$ & $3.5 \times 10^{-3}$ \\
\hline $\begin{array}{l}\text { Shallow uniform donor density ND } \\
\left(1 / \mathrm{cm}^{3}\right)\end{array}$ & 0 & $5.48 \times 10^{15}$ & $1 \times 10^{13}$ & $2.93 \times 10^{17}$ & $2.6 \times 10^{18}$ \\
\hline Shallow uniform acceptor density & $9 \times 10^{21}$ & 0 & 0 & 0 & 0 \\
\hline
\end{tabular}


NA (1/cm3)

Capture cross section electrons

$2 \times 10^{-14}$

$2 \times 10^{-14}$

$2 \times 10^{-14}$

$2 \times 10^{-14}$

$2 \times 10^{-14}$

$\left(\mathrm{cm}^{2}\right)$ and capture cross section holes $\left(\mathrm{cm}^{2}\right)$

Energy level with respect to

0.9

0.7

0.53

1.050

0.85

Reference (eV)

Total Defect $\mathrm{N}_{\mathrm{t}}\left(1 / \mathrm{cm}^{3}\right)$

$1 \times 10^{15}$

$1 \times 10^{14}$

$2.5 \times 10^{19}$

$1 \times 10^{15}$

$1 \times 10^{15}$

Table 2. Numerical parameters taken for different HTM [14,16,17,18,19]

\begin{tabular}{lccc}
\hline Parameters & PEDOT: PSS & CuI & CZTSe \\
\hline Thickness $(\mu \mathrm{m})$ & 0.03 & 0.03 & 0.03 \\
Bandgap $(\mathrm{eV})$ & 1.6 & 2.98 & 1.4 \\
Electron affinity $(\mathrm{eV})$ & 3.5 & 2.1 & 4.1 \\
Dielectric permittivity (relative) & 3.0 & 6.5 & 9.0 \\
$\mathrm{CB}$ effective density of states $\left(1 / \mathrm{cm}^{3}\right)$ & $1 \times 10^{22}$ & $2.8 \times 10^{19}$ & $2.2 \times 10^{18}$ \\
VB effective density of states $\left(1 / \mathrm{cm}^{3}\right)$ & $1 \times 10^{22}$ & $1 \times 10^{19}$ & $1.8 \times 10^{19}$ \\
Electron thermal velocity $(\mathrm{cm} / \mathrm{s})$ & $1 \times 10^{7}$ & $1 \times 10^{7}$ & $1 \times 10^{7}$ \\
Hole thermal velocity $(\mathrm{cm} / \mathrm{s})$ & $1 \times 10^{7}$ & $1 \times 10^{7}$ & $1 \times 10^{7}$ \\
Electron mobility $\left(\mathrm{cm}^{2} / \mathrm{Vs}\right)$ & $4.5 \times 10^{-4}$ & $1.7 \times 10^{-4}$ & $1 \times 10^{2}$ \\
Hole mobility $\left(\mathrm{cm}^{2} / \mathrm{Vs}\right)$ & $9.9 \times 10^{-5}$ & $2.0 \times 10^{-4}$ & 12.5 \\
Shallow uniform donor density ND $\left(1 / \mathrm{cm}^{3}\right)$ & 0 & 0 & 0 \\
Shallow uniform acceptor density NA $\left(1 / \mathrm{cm}^{3}\right)$ & $1 \times 10^{20}$ & $1 \times 10^{18}$ & $1 \times 10^{19}$ \\
Capture cross section electrons $\left(\mathrm{cm}^{2}\right)$ and capture cross section holes & $2 \times 10^{-14}$ & $2 \times 10^{-14}$ & $2 \times 10^{-14}$ \\
$\left.\mathrm{~cm}^{2}\right)$ & & & 0.9 \\
Energy level with respect to Reference $(\mathrm{eV})$ & 0.9 & $1 \times 10^{15}$ & $1 \times 10^{15}$ \\
Total Defect $\mathrm{N}_{\mathrm{t}}\left(1 / \mathrm{cm}^{3}\right)$ & $1 \times 10^{15}$ & & 0.9 \\
\hline
\end{tabular}

\section{RESULTS AND DISCUSSION}

In this section, we analyze the four structures with different hole transport materials (HTMs) to understand the behavior of solar cells. In the simulation, we worked on how some fundamental parameters of photovoltaic like defect density, operating temperature, the thickness of absorber layer, and bandgap of four different hole transport material influence the performance of the device.

\section{A. Comparative study of different HTM for the same thickness of absorber layer and defect scenario}

In this subsection, we have inspected with optimization of hole transport materials i.e., PEDOT: PSS, $\mathrm{Cu}_{2} \mathrm{O}, \mathrm{CuI}_{1} \mathrm{CZTSe}$. We have simulated these hole transport materials to choose the best-suited HTM and determine its optimum thickness. Table 1 and Table 2 show the various parameters of HTM. Out of four HTM, Cu2O provides the maximum power conversion efficiency as compared to other HTMs. It has the highest charge carrier mobility due to which more carriers are extracted and more current is produced. From figure 2, it is also shown that it has better band alignment with the absorber layer. After simulating perovskite solar cells with $\mathrm{HTMs}, \mathrm{Cu}_{2} \mathrm{O}$ gives the best performance parameters with the highest power conversion efficiency of $18.78 \%$.

\section{B. Analysis of HTMs with the variation of thickness of absorber layer.}

To observe the effect of absorber layer thickness on the solar cell, we have varied the thickness of $\left(\mathrm{FA}_{0.9} \mathrm{EA}_{0.1}\right)_{0.98} \mathrm{EDA}_{0.01} \mathrm{SnI}_{3}$ from $150 \mathrm{~nm}$ to $550 \mathrm{~nm}$ keeping all other parameters same. The results are shown in figure 3 . When a thin layer is used, low photocurrent is produced which results due to less absorption, however, extraction is high. Power Conversion Efficiency is increasing with the thickness of perovskite absorber layer because more material is exposed to sunlight and therefore more energy will be absorbed in this layer [5]. As a result, more electron-hole pairs are created with enhanced mobility. We can also see the decrease in fill factor with the increase in the thickness of the absorber layer. This is mainly due to the internal 
recombination inside the perovskite material that is generated due to electron and hole charge carriers, which do not permit an adequate period for charge carriers to develop conduction band at perovskite material [6]. The tin-based absorber layer is an excellent absorber material to achieve high power conversion efficiency at a low cost.
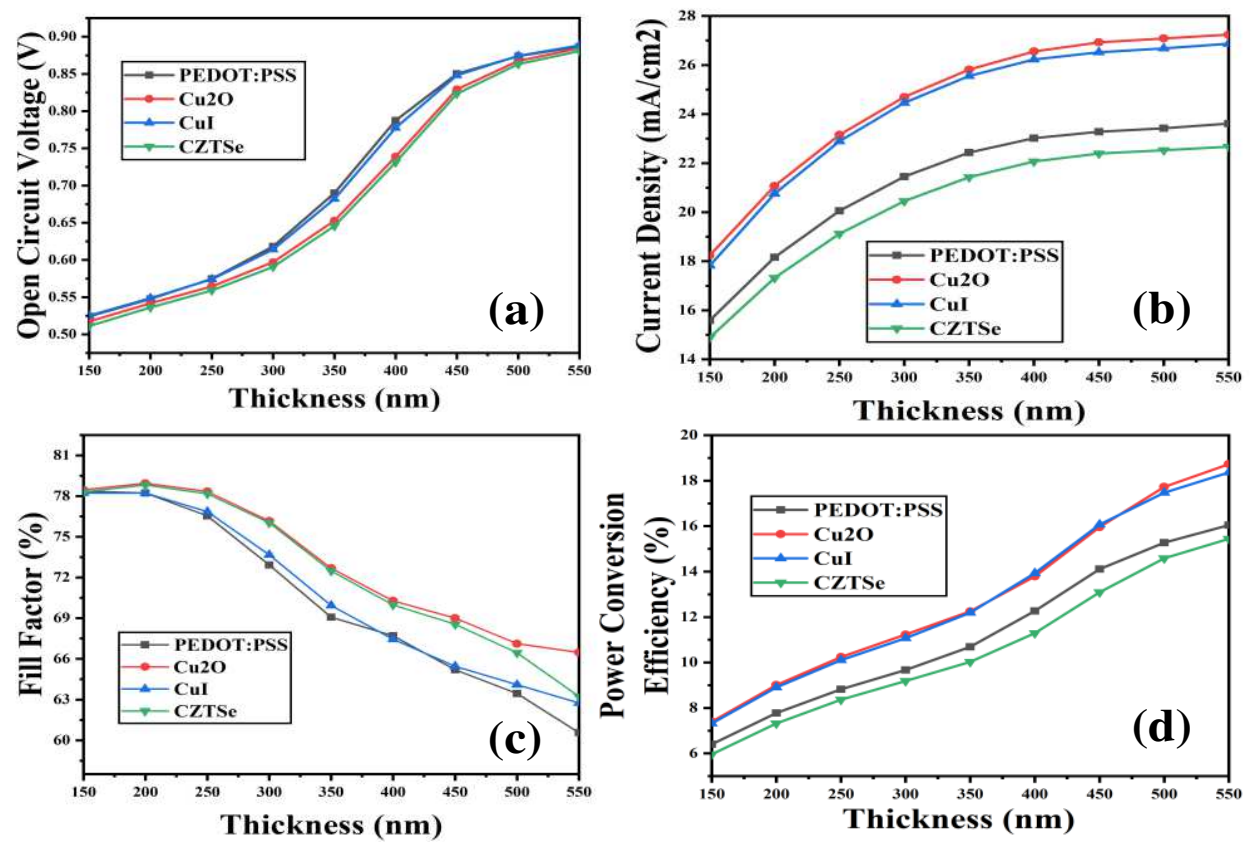

Fig. 3. Variation in the absorber thickness with respect to (a) Open Circuit Voltage, (b) Short circuit current density, (c) Fill factor, (d) Power Conversion Efficiency, keeping the same thickness of ETL and HTL.

\section{Effect of variation in defect density of absorber layer on perovskite solar cell}

The defect density is considered as one of the significant parameters of the individual layer. It plays an important role in the performance of the solar cell as it increases the recombination center in the layer. The Shockley-Read-Hall (SRH) recombination model has been employed to study the effect of defect density of the absorber layer on the performance of solar cells as given in equation 1 and equation 2 [17].

$$
\begin{aligned}
& R_{S R H}=\frac{n p-n_{i}^{2}}{\tau_{p}\left(n+n_{i}\right)+\tau_{n}\left(p+p_{i}\right)} \\
& \tau_{n \cdot p}=\frac{1}{\sigma \vartheta_{t h, n, p} N_{t}} \ldots \ldots \ldots \ldots \ldots \ldots \ldots \ldots \ldots \ldots \ldots \ldots
\end{aligned}
$$

Where, $\mathrm{R}_{\mathrm{SRH}}=$ Shockley-Read-Hall recombination rate.

$\mathrm{n}$ and $\mathrm{p}=$ Electron, hole concentration,

$\sigma_{p}, \sigma_{n}=$ lifetime of hole and electron.

The initial defect density of the perovskite layer is considered as $10^{16} \mathrm{~cm}^{-3}$. Then, we started decreasing it below $10^{16}-10^{14} \mathrm{~cm}^{-}$

${ }^{3}$. We saw that power conversion efficiency starts increasing with decreasing defect density. It has been observed that if defect density of absorber layer is varied from $10^{14}-10^{19}$ as shown in figure 4 . The $\mathrm{Voc}_{\mathrm{oc}} \mathrm{Cu}_{2} \mathrm{O}$ has been decreased from $0.88 \mathrm{~V}$ to $0.52 \mathrm{~V}$, Jsc varies from $27.24 \mathrm{~mA} / \mathrm{cm} 2$ to $14.71 \mathrm{~mA} / \mathrm{cm} 2$, Fill Factor varies from $77.93 \%$ to $58.23 \%$, and efficiency ( $\mathrm{n} \%$ ) varies from $18.78 \%$ to $4.51 \%$. 

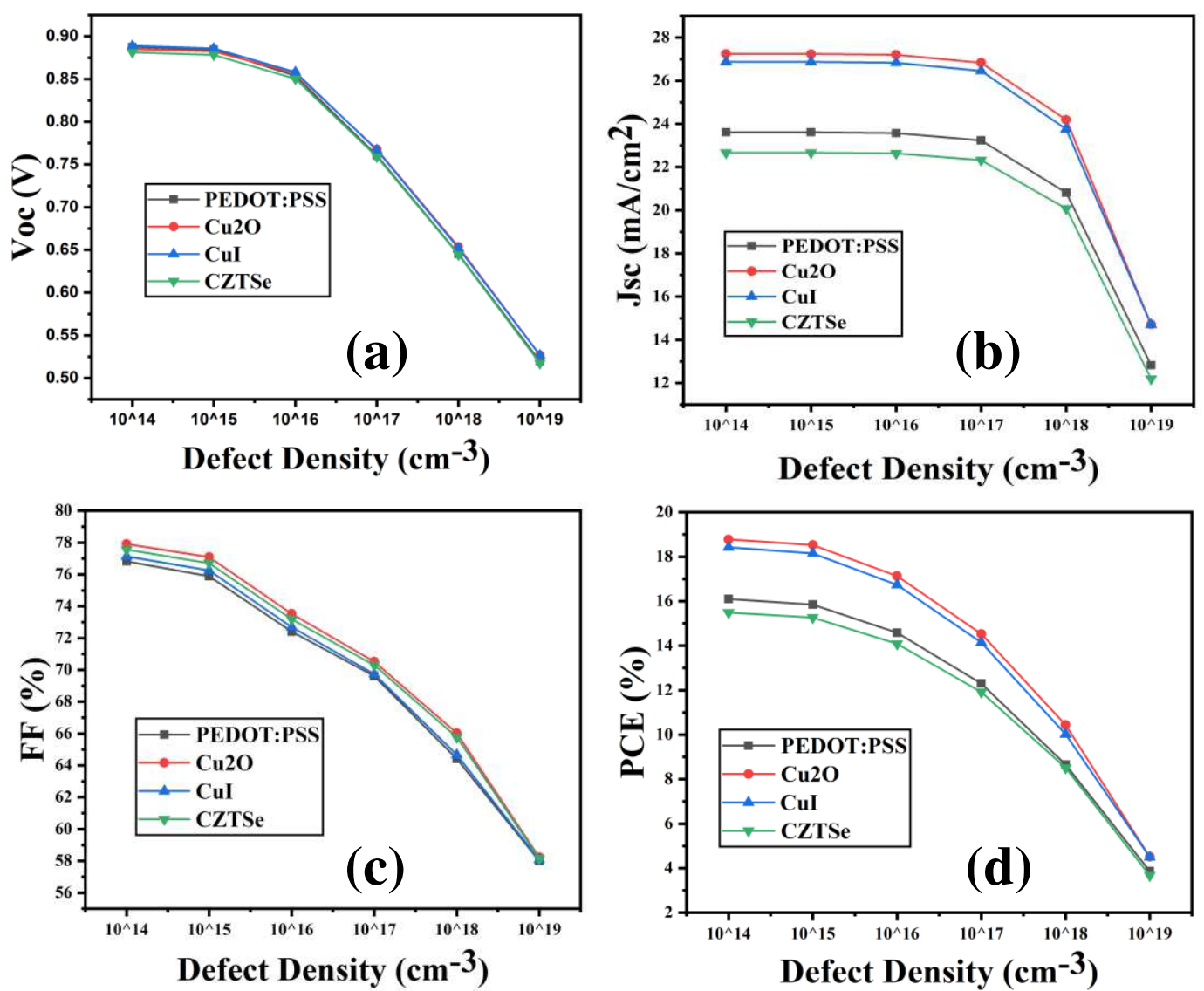

Fig. 4. Variation in the Defect density of perovskite layer with respect to (a) Open circuit voltage (b) short circuit current density (c) Fill factor, (d) Power conversion efficiency.

Increase in defect density of the absorber layer will create more recombination centers within the absorber layer due to which more carriers are getting recombined within the absorber layer [9]. Also, as the defect density of absorber layer increases, it will reduce the lifetime of carriers because they are recombined inside the absorber layer and no more carriers are left for extraction which in turn reduces the overall device performance of solar cells as per the equation (1) and equation (2). Moreover, with the increase in defect density, recombination centers also increase which decreases the shunt resistance of the device which in turn reduces the open-circuit voltage (Voc) [11]. Hence, can conclude from the above analysis that for better device performance of the solar cell, the numeric value for defect density of the perovskite layers should be in the order of $\sim 1 \times 10^{14} \mathrm{~cm}^{-3}$ as with the increase in this parameter, the photovoltaic performance has been reduced.

\section{Effect of operating temperature on the performance of perovskite solar cell}

There is a need to understand the effect of operating temperature on the performance of the solar cell. Generally, solar cells are installed in the outer environment where solar panels are continuously illuminated with sunlight. Due to this continuous illumination, it will increase the cell temperature to greater than the room temperature. We have tried to investigate the effect of variation in operating temperature on the performance of the solar cell. The temperature is varied from $200 \mathrm{~K}$ to $500 \mathrm{~K}$. It has been observed that Voc has been reduced from 1.03 to $0.38 \mathrm{~V}$, Jsc reduces from 27.50 to $26.42 \mathrm{~mA} / \mathrm{cm}^{2}$, FF varies from 80.74 to $57.82 \%$ and power conversion efficiency varies from $22.95 \%$ to $5.86 \%$ for $\mathrm{Cu}_{2} \mathrm{O}$. At higher temperatures, the bandgap reduces due to which more recombination of excitons (electrons and holes) will take place which will further result in the reduction of Voc [7]. Due to an increase in temperature, defects also increase, which will cause reduction in FF and PCE of the device. The results for device ITO/Cu $\mathrm{Cu}_{2} \mathrm{O}\left(\mathrm{FA}_{0.9} \mathrm{EA}_{0.1}\right)_{0.98} \mathrm{EDA}_{0.01} \mathrm{SnI}_{3} / \mathrm{IDL} / \mathrm{PCBM} / \mathrm{C} 60 / \mathrm{Au}$ are shown in figure 5 . 

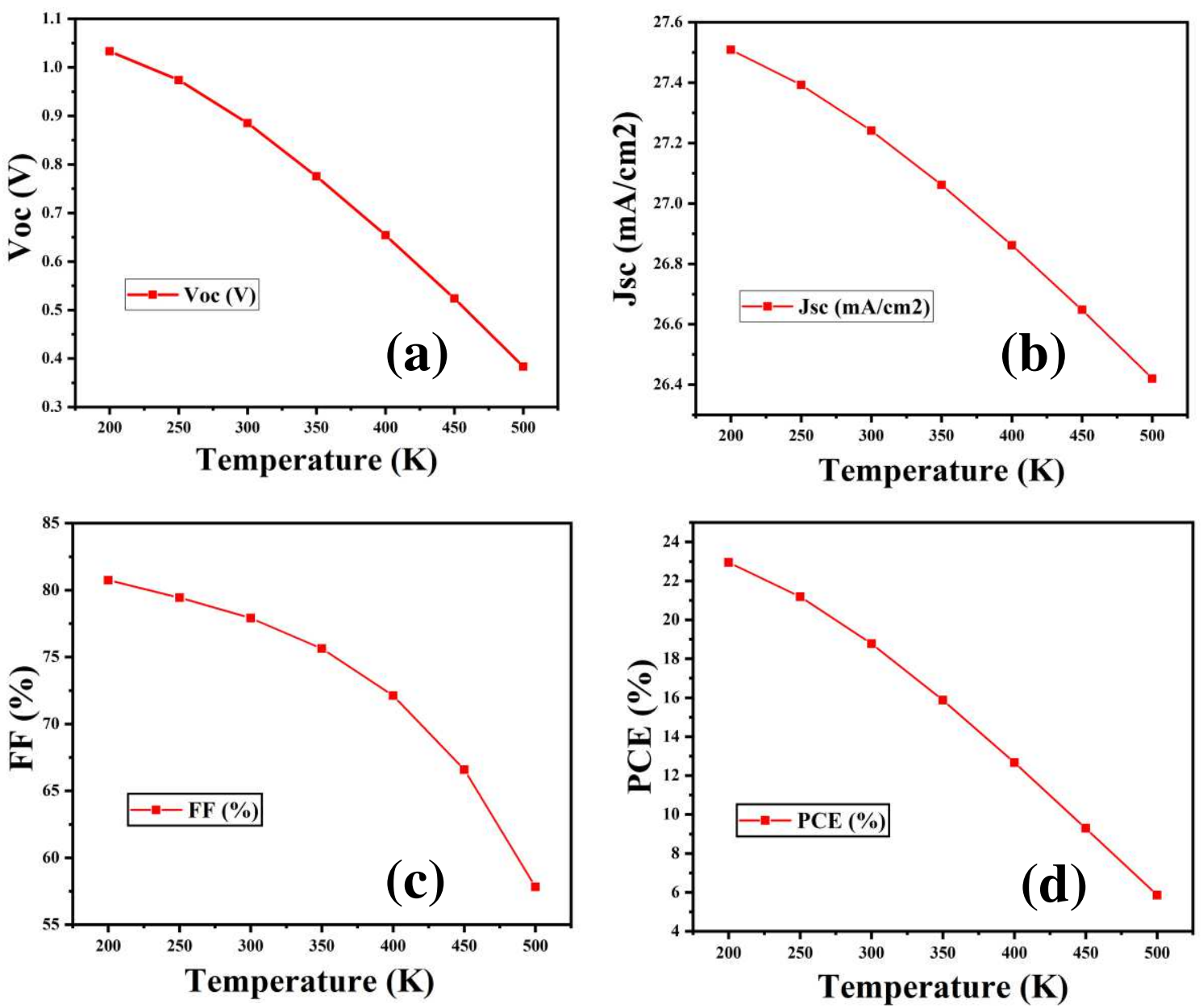

Fig. 5. The behavior of (a) Open circuit voltage (b) Short circuit current density, (c) Fill factor, (d) Power conversion efficiency in variation with the operating temperature of perovskite solar cell.

\section{E. J-V and Quantum efficiency}

Current density-voltage characteristics (J-V) and Quantum efficiency curves are very imperative for the analysis of solar cell performance. For each device structure having PEDOT: PSS, $\mathrm{Cu}_{2} \mathrm{O}, \mathrm{CuI}, \mathrm{CZTSe}$ hole transport materials, the J-V Characteristics, and quantum efficiency are shown in figure 6. $\left(\mathrm{FA}_{0.9} \mathrm{EA}_{0.1}\right)_{0.98} \mathrm{EDA}_{0.01} \mathrm{SnI}_{3}$ based perovskites have a very narrow bandgap. So absorption shifts towards the near infrared region (NIR) [20-22]. Here quantum efficiency curves are covering the whole visible spectrum (400-750nm) of solar radiation. By analyzing QE curve, broad absorption maximum of up to $99 \%$ with $\mathrm{Cu}_{2} \mathrm{O}$ has achieved in this simulation work.
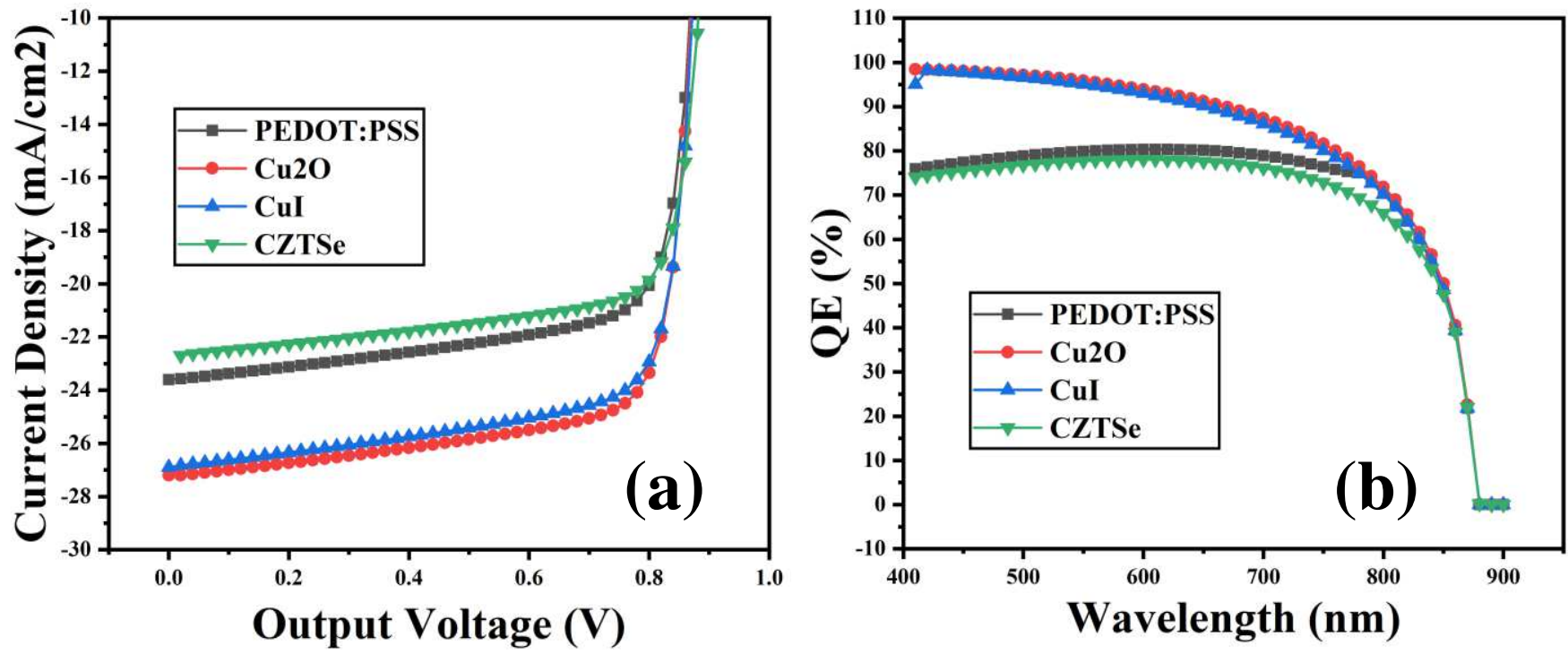
Fig. 6. (a) J-V Characteristics of Perovskite solar cell, (b) Percentage of quantum efficiency with variation in wavelength.

The general structure of tin-based perovskite solar cells consists of $\left(\mathrm{FA}_{0.9} \mathrm{EA}_{0.1}\right)_{0.98} \mathrm{EDA}_{0.01} \mathrm{SnI}_{3}$ absorber layer. Various compositions of the absorber layer have been simulated. $\left(\mathrm{FA}_{1-\mathrm{x}} \mathrm{EA}_{\mathrm{x}}\right)_{0.98} \mathrm{EDA}_{0.01} \mathrm{SnI}_{3}$ perovskite with $\mathrm{x}=0.1,0.2,0.3,0.4$ are taken for deciding the best composition for perovskite layer. Table 3 shows that at $\mathrm{x}=0.1$, we have reported the maximum efficiency of 18.78 .

Table 3 Different composition of the perovskite absorber layer

\begin{tabular}{|l|c|c|c|c|}
\hline $\mathrm{FA}_{1-\mathrm{x}} \mathrm{EA}_{\mathrm{x}}$ & Voc $(\mathrm{V})$ & Jsc $(\mathrm{mA} / \mathrm{cm} 2)$ & FF (\%) & PCE (\%) \\
\hline $\mathrm{FA}_{0.9} \mathrm{EA}_{0.1}$ & 0.8851 & 27.24 & 77.91 & 18.78 \\
\hline $\mathrm{FA}_{0.8} \mathrm{EA}_{0.2}$ & 0.9141 & 26.17 & 78.07 & 18.68 \\
\hline $\mathrm{FA}_{0.7} \mathrm{EA}_{0.3}$ & 0.9336 & 25.66 & 78.01 & 18.69 \\
\hline $\mathrm{FA}_{0.6} \mathrm{EA}_{0.4}$ & 0.9434 & 25.23 & 78.01 & 18.57 \\
\hline
\end{tabular}

Table 4 shows the optimized parameters of solar cells with four different hole transport materials.

Table 4 Performance parameters of perovskite solar cell with different HTMs

\begin{tabular}{|c|c|c|c|c|c|}
\hline HTMs & Voc $(\mathbf{V})$ & Jsc $(\mathbf{m A} / \mathbf{c m} 2)$ & FF (\%) & PCE (\%) & Reference \\
\hline PEDOT: PSS & 0.8877 & 23.61 & 76.82 & 16.10 & This Work \\
\hline $\mathrm{CuI}$ & 0.8889 & 26.87 & 77.13 & 18.42 & This Work \\
\hline $\mathrm{CZTSe}$ & 0.8813 & 22.66 & 77.56 & 15.49 & This Work \\
\hline $\mathrm{Cu}_{2} \mathrm{O}$ & 0.8851 & 27.24 & 77.91 & 18.78 & This Work \\
\hline PEDOT: PSS & 0.8400 & 20.32 & 78.00 & 13.24 & {$[14]$} \\
\hline $\mathrm{Cu}_{2} \mathrm{O}$ & 1.340 & 15.55 & 82.73 & 18.01 & {$[17]$} \\
\hline $\mathrm{CuI}$ & 1.050 & 15.55 & 81.23 & 13.90 & {$[17]$} \\
\hline PEDOT: PSS & 0.890 & 22.79 & 65.28 & 13.35 & {$[23]$} \\
\hline
\end{tabular}

Figure 7 shows the comparison between the experimental [14] and simulated results. It is shown from the figure that J-V and $\mathrm{QE}$ curves which are obtained for both experimental and simulated results are somewhat identical to each other.
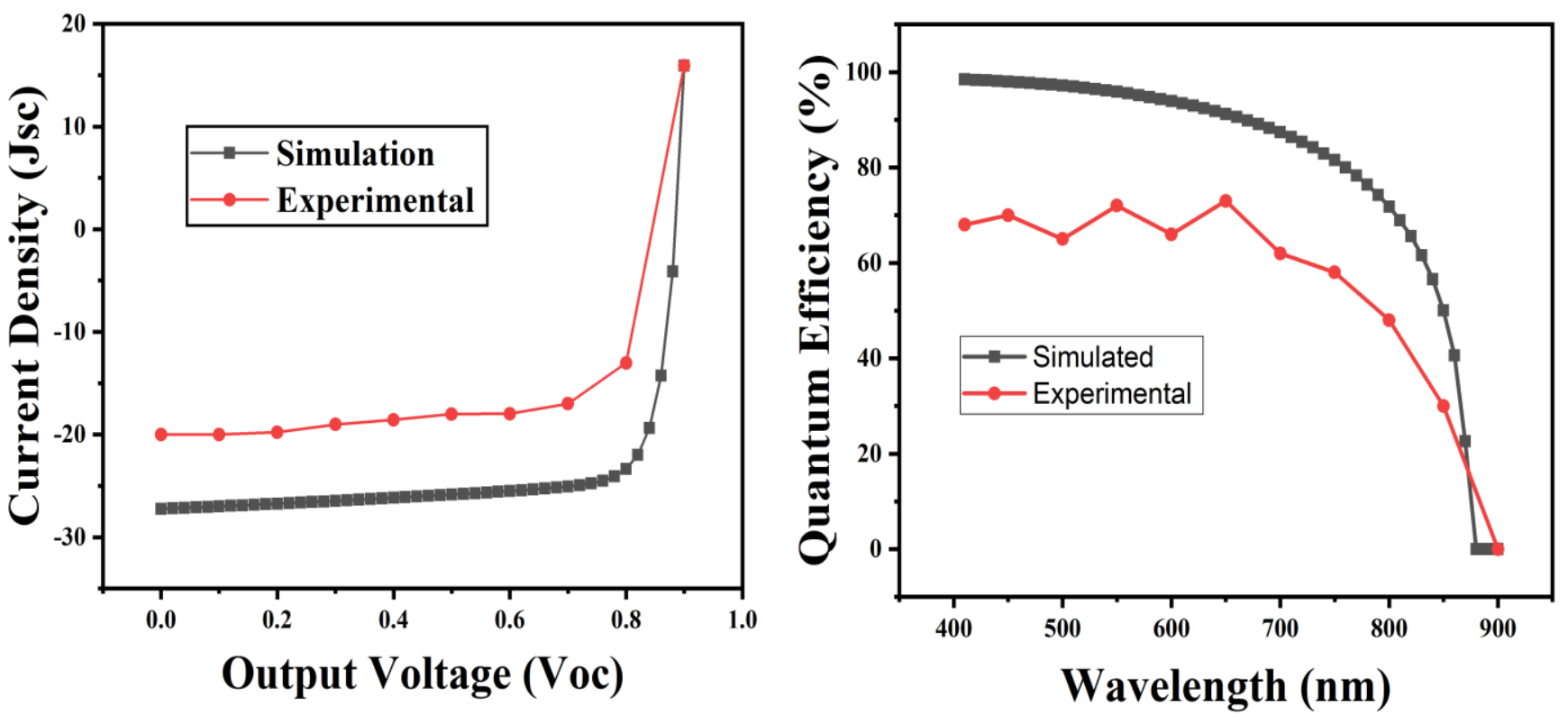

Fig. 7. J-V and QE-Wavelength curves obtained for both simulation and experimental work. 


\section{CONCLUSION}

In this study, we have optimized the performance of lead-free perovskite solar cell for different HTL. This research work comprises the device simulation of lead-free perovskite solar cell. It is obtained from the simulation results, that $\mathrm{Cu}_{2} \mathrm{O}$ as $\mathrm{HTL}$ shows higher PCE as compare to PEDOT: PSS, CuI, CZTSe based perovskite structure. It has been reported that $\mathrm{Cu}_{2} \mathrm{O}$ has a better band alignment with the absorber layer. By optimization the device parameters we have achieved Voc $=0.8851 \mathrm{~V}$, $\mathrm{Jsc}=27.24 \mathrm{~mA} / \mathrm{cm}^{2}, \mathrm{FF}=77.91 \%$, and $\mathrm{PCE}=18.78 \%$ for $\mathrm{FTO} / \mathrm{Cu}_{2} \mathrm{O} /\left(\mathrm{FA}_{0.9} \mathrm{EA}_{0.1}\right)_{0.98} \mathrm{EDA}_{0.01} \mathrm{SnI}_{3} / \mathrm{IDL} / \mathrm{PCBM} / \mathrm{C} 60 / \mathrm{Au}$ device structure. The defect density of the perovskite absorber layer is found to be $1 \times 10^{14} \mathrm{~cm}^{-3}$ for better performance. A further effect of operating temperature has also been studied to investigate the performance of tin-based perovskite solar cell and the optimized results have been achieved at $300 \mathrm{~K}$. With the increase in temperature, the device starts degrading due to infusion of certain defects which will cause instability issues. These results represent the potential of $\left(\mathrm{FA}_{0.9} \mathrm{EA}_{0.1}\right)_{0.98} \mathrm{EDA}_{0.01} \mathrm{SnI}_{3}$ based solar cell (lead free) which can provide support to the research community to design more stable and environment friendly solar cell.

\section{ACKNOWLEDGMENT}

The authors would like to thank Marc Burgelman, University of Ghent, for SCAPS 1-D simulation software.

\section{REFERENCES}

[1] Sahli, F., Werner, J., Kamino, B. A., Bräuninger, M., Monnard, R., Paviet-Salomon, B., ... \& Ballif, C. (2018). Fully textured monolithic perovskite/silicon tandem solar cells with $25.2 \%$ power conversion efficiency. Nature materials, 17(9), 820-826.

[2] Jiang, Q., Zhao, Y., Zhang, X., Yang, X., Chen, Y., Chu, Z., ... \& You, J. (2019). Surface passivation of perovskite film for efficient solar cells. Nature Photonics, 13(7), 460-466.

[3] Yang, W. S., Park, B. W., Jung, E. H., Jeon, N. J., Kim, Y. C., Lee, D. U., ... \& Seok, S. Il Science 2017, 356, 1376-1379.

[4] Haase, F., Hollemann, C., Schäfer, S., Merkle, A., Rienäcker, M., Krügener, J., ... \& Peibst, R. (2018). Laser contact openings for local poly-Si-metal contacts enabling 26.1\%-efficient POLO-IBC solar cells. Solar Energy Materials and Solar Cells, 186, 184-193.

[5] Zhou, D., Zhou, T., Tian, Y., Zhu, X., \& Tu, Y. (2018). Perovskite-based solar cells: materials, methods, and future perspectives. Journal of Nanomaterials, 2018

[6] Hasan, S. A. U., Lee, D. S., Im, S. H., \& Hong, K. H. (2020). Present Status and Research Prospects of Tin-based Perovskite Solar Cells. Solar RRL, 4(2), 1900310.

[7] Dixit, H., Punetha, D., \& Pandey, S. K. (2021). Comparative Study and Analysis of Different Perovskite Solar Cells with Inverted Architecture. In Computational Mathematics, Nanoelectronics, and Astrophysics: CMNA 2018, Indore, India, November 1-3 (pp. 125-135). Springer Singapore.

[8] Kumar, M., Raj, A., Kumar, A., \& Anshul, A. (2020). An optimized lead-free formamidinium Sn-based perovskite solar cell design for high power conversion efficiency by SCAPS simulation. Optical Materials, 108, 110213.

[9] Liu, W. W., Wu, T. H., Liu, M. C., Niu, W. J., \& Chueh, Y. L. (2019). Recent Challenges in Perovskite Solar Cells Toward Enhanced Stability, Less Toxicity, and Large-Area Mass Production. Advanced Materials Interfaces, 6(9), 1801758.

[10] Ke, W., Stoumpos, C. C., \& Kanatzidis, M. G. (2019). "Unleaded" perovskites: status quo and future prospects of tin-based perovskite solar cells. Advanced Materials, 31(47), 1803230.

[11] Cao, J., \& Yan, F. (2021). Recent progress in tin-based perovskite solar cells. Energy \& Environmental Science, 14(3), $1286-1325$.

[12] Song, T. B., Yokoyama, T., Logsdon, J., Wasielewski, M. R., Aramaki, S., \& Kanatzidis, M. G. (2018). Piperazine suppresses self-doping in CsSnI3 perovskite solar cells. ACS Applied Energy Materials, 1(8), 4221-4226.

[13] Liu, T., Zhao, X., Li, J., Liu, Z., Liscio, F., Milita, S., ... \& Fenwick, O. (2019). Enhanced control of self-doping in halide perovskites for improved thermoelectric performance. Nature communications, 10(1), 1-9.

[14] Nishimura, K., Kamarudin, M. A., Hirotani, D., Hamada, K., Shen, Q., Iikubo, S., ... \& Hayase, S. (2020). Lead-free tin-halide perovskite solar cells with $13 \%$ efficiency. Nano Energy, 74, 104858.

[15] Pandey, S. K., \& Somay, S. (2021). Device Engineering Approach Toward Stable, Efficient, and Eco-Friendly Perovskite Solar Cell. IEEE Transactions on Electron Devices, 68(3), 1142-1148.

[16] Bag, A., Radhakrishnan, R., Nekovei, R., \& Jeyakumar, R. (2020). Effect of absorber layer, hole transport layer thicknesses, and its doping density on the performance of perovskite solar cells by device simulation. Solar Energy, 196, 177-182.

[17] Singh, N., Agarwal, A., \& Agarwal, M. (2021). Numerical simulation of highly efficient lead-free perovskite layers for the application of all-perovskite multi-junction solar cell. Superlattices and Microstructures, 149, 106750.

[18] Minemoto, T., Kawano, Y., Nishimura, T., Shen, Q., Yoshino, K., Iikubo, S., ... \& Chantana, J. (2020). Theoretical analysis of band alignment at back junction in Sn-Ge perovskite solar cells with inverted pin structure. Solar Energy Materials and Solar Cells, $206,110268$.

[19] Ahmed, S., Jannat, F., Khan, M. A. K., \& Alim, M. A. (2021). Numerical development of eco-friendly Cs2TiBr6 based perovskite solar cell with allinorganic charge transport materials via SCAPS-1D. Optik, 225, 165765.

[20] Teimouri, R., \& Mohammadpour, R. (2018). Potential application of CuSbS2 as the hole transport material in perovskite solar cell: a simulation study. Superlattices and Microstructures, 118, 116-122.

[21] Lin, J., Lai, M., Dou, L., Kley, C. S., Chen, H., Peng, F., ... \& Yang, P. (2018). Thermochromic halide perovskite solar cells. Nature materials, 17(3), 261-267.

[22] Dixit, Himanshu, Deepak Punetha, and Saurabh Kumar Pandey. "Improvement in performance of lead free inverted perovskite solar cell by optimization of solar parameters." Optik 179 (2019): 969-976.

[23] Pathak, C., \& Pandey, S. K. (2020). Design, performance, and defect density analysis of efficient eco-friendly perovskite solar cell. IEEE Transactions on Electron Devices, 67(7), 2837-2843. 